\title{
(1) Guilt: One Story Behind Psychological and Sexual Health
}

\author{
Luci A. Martin, M. S. \& Mark Vosvick, Ph.D.
}

University of North Texas

Freud described guilt as the result of a humanity that lives in a civilizatio - Freud described guilt as the result of a humanity that lives in a civilizan
that does not allow us to act impulsively toward our desires and fantasies that does not

(Kahn, 2002).
$>$ Guilt has been examined over the years for its role in psychological and sexual health from many perspectives (Faiver, O'Brien, \& Ingersoll, 2000). $>$ Kahn (2002) argued that without guilt, people might act freely, pursuing pleasures without negative emotions

- Such ungoverned pleasure seeking behaviors could result in legal action, isolation, or disease

$>$ Not all researchers agree on guilt's role in psychological and sexual health (Ellis, 1960; Mowrer, 1960)

It is important to examine guilt complexly, the role of guilt in psychologica health as well as the role of guilt in behaviors that could result in negative harmful consequences

$>$ Our study examines the specific relationship three types of guilt have witt markers of psychological and sexual health to provide an empirical basis to markers of psychological and sexual health to provide an empirical ba:
help understand the complex role guilt plays in college students' lives.

\section{Hypotheses}

H1: Sex-related guilt, guilty conscious and hostile guilt will be negatively related to psychological health

H2: Sex-related guilt will be positively associated with markers of sexual health

H3: Hostile guilt and guilty conscious will be negatively related to measures of sexual health

\begin{tabular}{|l|}
\hline \multicolumn{1}{|c|}{ Methc } \\
\hline \hline$>$ Participants completed a computerized \\
battery of self-report measures including \\
demographic, sexual and psychological \\
information. \\
$>$ A diverse non-clinical sample ( $\mathrm{N}=662$, \\
$70 \%$ female, $60 \%$ European-American, \\
$20 \%$ African-American, $9 \%$ Latinos, $11 \%$ \\
"Other") was drawn from a college \\
student population at a large Southern \\
university. \\
$>$ Criteria for inclusion required that all \\
participants were enrolled as \\
undergraduate students and 18 years of \\
age or older. \\
> The average age was 21 years (SD = \\
3.66, Range $18-54$ ). \\
$>$ This sample predominantly self- \\
reported as heterosexual (94\%). \\
$>$ Sixty-nine percent of the sample \\
reported that they were single/dating. \\
$>$ Sexual health consisted of yes/no \\
questions, with the exception of number \\
of partners and condom embarrassment. \\
\hline
\end{tabular}

\section{Method}

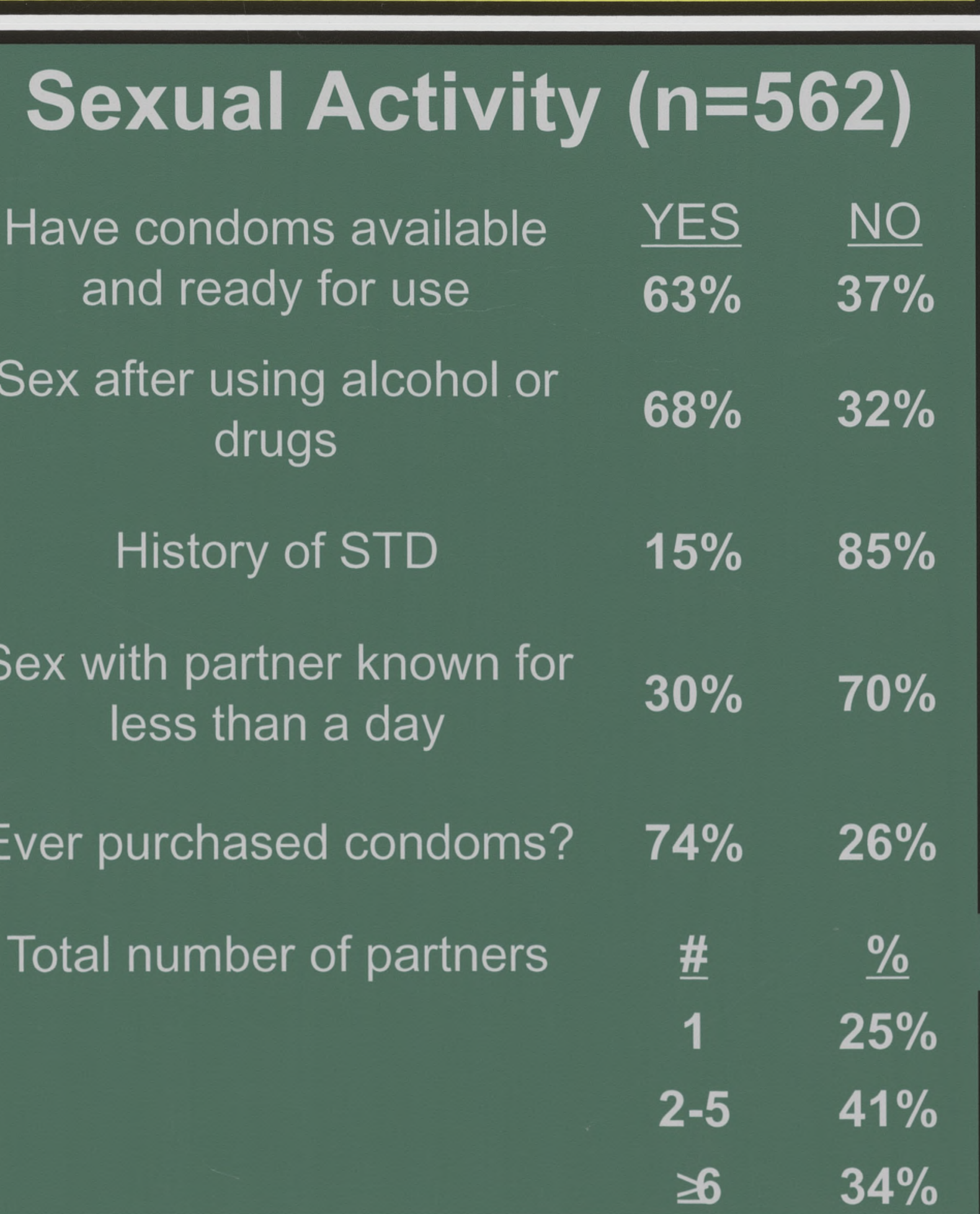

Since our measures of psychological categorical and continuous data as
outcome measures, we conducted both multiple linear regressions and binary logistic regressions to test our mode
Each model controlled for gender and ethnicity

\begin{tabular}{|c|c|c|c|c|}
\hline Measures & Sample Question & Mean (SD) & Range & $\alpha$ \\
\hline \multirow{3}{*}{$\begin{array}{l}\text { Revised Mosher Guilt } \\
\text { Inventory (Mosher, 1968) } \\
\text { 1. Sex Guilt } \\
\text { 2. Hostile Guilt } \\
\text { 3. Guilty Conscious }\end{array}$} & $\begin{array}{l}\text { 1. "Masturbation is wrong and } \\
\text { will ruin you." }\end{array}$ & $\begin{array}{l}111.67 \\
(39.37)\end{array}$ & $0-300$ & \multirow{3}{*}{0.93} \\
\hline & $\begin{array}{l}\text { 2. "After an outburst of ange } \\
\text { I am sorry and say so." }\end{array}$ & $\begin{array}{l}136.92 \\
(26.28)\end{array}$ & $0-252$ & \\
\hline & $\begin{array}{l}\text { 3. "I punish myself when I do } \\
\text { wrong and don't get caught." }\end{array}$ & $\begin{array}{r}65.86 \\
(11.64)\end{array}$ & $0-132$ & \\
\hline $\begin{array}{l}\text { Rosenberg Self-Esteem } \\
\text { Scale (Rosenberg, 1965) }\end{array}$ & $\begin{array}{l}\text { "I take a positive attitude } \\
\text { toward-myself." }\end{array}$ & $\begin{array}{l}31.45 \\
(5.10)\end{array}$ & $10-40$ & 0.76 \\
\hline $\begin{array}{l}\text { Perceived Stress Scale } \\
\text { (Cohen,Kamarck, \& } \\
\text { Mermelstein, 1983) }\end{array}$ & $\begin{array}{l}\text { "How often have you felt } \\
\text { nervous and 'stressed??" }\end{array}$ & $\begin{array}{l}25.78 \\
(6.83)\end{array}$ & $0-56$ & 0.82 \\
\hline $\begin{array}{l}\text { Center for Epidemiologic } \\
\text { Studies Depression Scale } \\
\text { (Radloff, 1977) }\end{array}$ & "I felt sad." & & $0-60$ & 0.90 \\
\hline $\begin{array}{l}\text { Condom Embarrassment } \\
\text { Scale (Vail Smith, Durham } \\
\text { \& Howard, 1992) }\end{array}$ & $\begin{array}{c}\text { "I am embarrassed or would } \\
\text { be embarrassed about burying } \\
\text { a condom from a drug store } \\
\text { near campus." }\end{array}$ & $\begin{array}{l}17.74 \\
(8.86)\end{array}$ & $8-40$ & 0.91 \\
\hline
\end{tabular}

\section{Results}
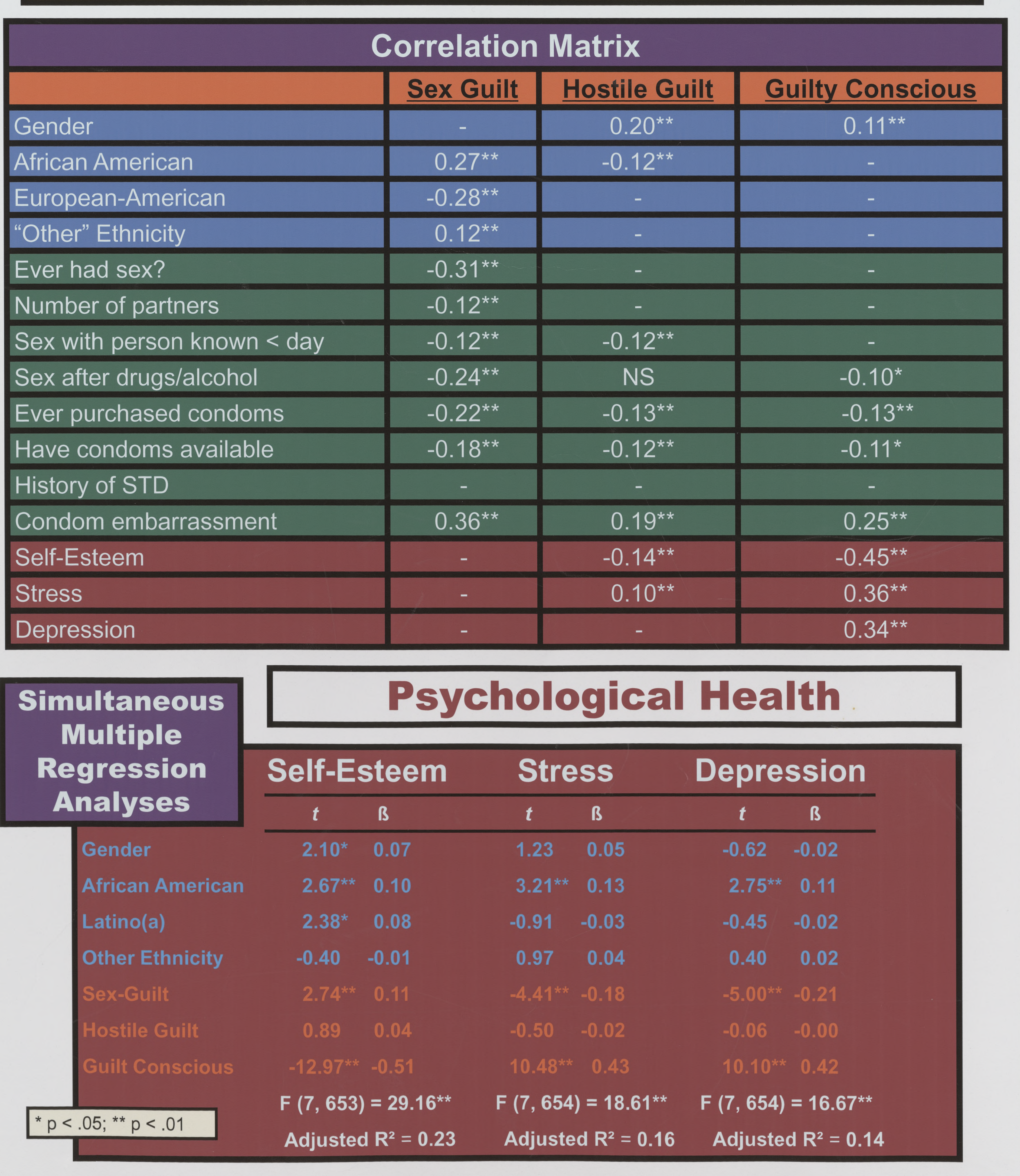

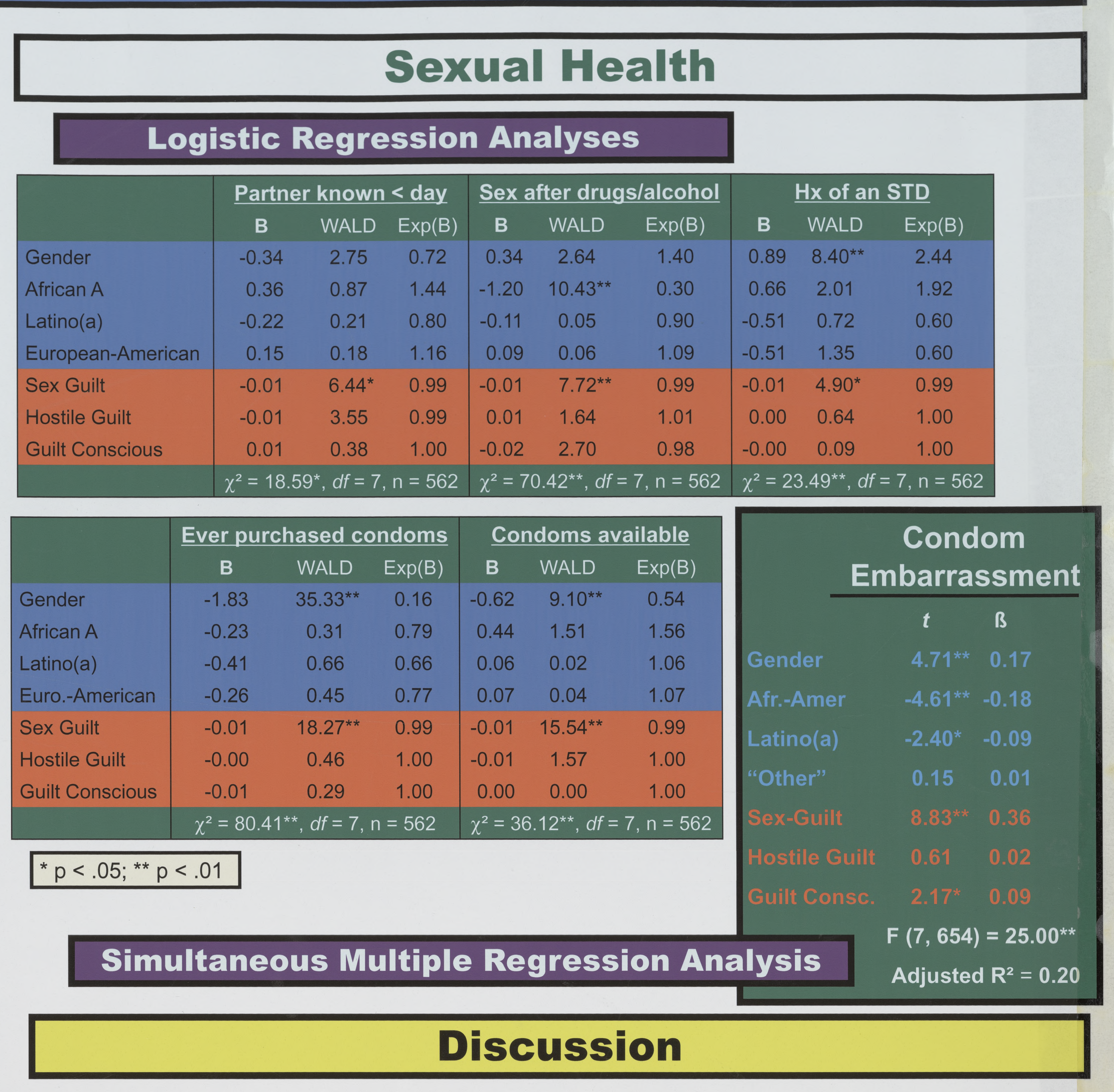

$>$ In conclusion, it appears that higher sex-related guilt and lower guilty conscience have the strongest relationship with psychological well-being. $>$ Our findings that the relationship between guilty conscious and psychological health are consistent with previous research (Faiver et al., 2004; Abramson et al., 1977).

$>$ Sex-related guilt has a less clear relationship with sexual health, with positive relationships with both risky and less risky behaviors and attitudes. Hostile guilt did not appear to play a significant role in either psychological or sexual health

$>$ Low sex-guilt has been linked to higher contraceptive and safe sex practices in women (Mosher \& Vonderheide, 1985), but few studies have examined the constructs of hostile and sex guilt in relation to health, therefore it is difficult to compare our findings.

$>$ Given the limited research available, it is important for researchers to continue to address the complex relationship between various forms of guil and health.

$>$ Our study is limited by retrospective, self-report data and consists of primarily female students, limiting generalization. We used a cross-sectional, correlational design, which does not allow us to infer causality.

$>$ Given the consequences of risky sexual behaviors and psychological illness, it is crucial that we understand which types of guilt are useful and which put individuals at risk, in order to design the best educational and psychotherapeutic interventions.

- Future studies need to examine the influence of such interventions on college student's sexual and psychological health.

Please see handout for references and acknowledgement. 